\title{
Design and Analysis of Butterfly Valve Disc Using Aluminium (1100) and AI-CNT4\% Composite Material
}

\author{
Syed Bava Bakrudeen $A^{*}$ and Balaji V
}

Department of Mechanical Engineering, College of Engineering and Technology,

Post Box No.1010, Aksum University, Axum, Ethiopia

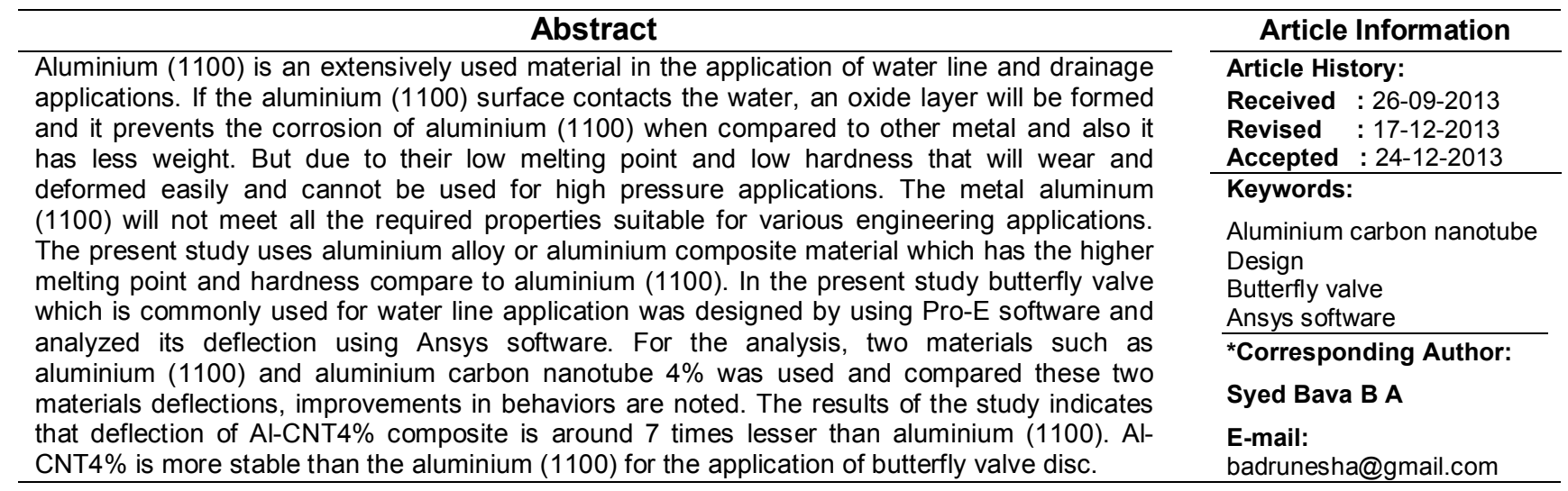

\section{INTRODUCTION}

In our practical applications commonly we use castiron for water line and sewage application. The cast iron is higher density. So it s weight is more, therefore it is a very big problem for transport and handling these metals. Instead of these we use PVC pipes, but commonly it cannot with stand high pressure. Aluminium (1100) is very good material for easy handling because of its low density and also aluminium (1100) has high corrosion resistance. Major drawback of aluminium (1100) is it deforms more, so it cannot with stand high pressure to overcome these behaviors we use aluminum composite which has an enhanced mechanical and thermal properties compare to aluminium (1100). Bayraktar et al., (2010) developed a new aluminium matrix composite reinforced with iron oxide $\left(\mathrm{Fe}_{3} \mathrm{O}_{4}\right)$ by using microwave sintering programme; he found that the density of the composite is increased compared to ordinary electrical sintering process (Bayraktar et al., 2010).

\section{Butterfly Valve}

A butterfly valve is a valve which can be used for isolating or regulating flow. The closing mechanism takes the form of a disk. Operation is similar to that of a ball valve, which allows for quick shut off. Butterfly valves are generally favoured because they are lower in cost to other valve designs as well as being lighter in weight, meaning less support is required. The disc is positioned in the centre of the pipe, passing through the disc is a rod connected to an actuator on the outside of the valve.
Rotating the actuator turns the disc either parallel or perpendicular to the flow. Butter fly valves are used in all types of pressure applications (Graham Brett et al., 2011).

\section{Metal Matrix Composite}

A metal matrix composite (MMC) is a composite material with at least two constituent parts, one being metal. The other material may be different metal or another material, such as a ceramic or organic compound. MMCs are made by dispersing a reinforcing material into metal matrix. For example of carbon fibers are commonly used in aluminium matrix to synthesize a composite. This composite having superior properties of carbon fibers and aluminium. So this composite poses low density and high strength (Eswai et al., 2006).

\section{Carbon Nano Tubes}

Carbon nanotubes (CNT) are allotropes of carbon with a cylindrical nano structure. Nanotubes have been constructed with length to diameter ratio up to $132,000,000: 1$. These are significantly larger than any other materials. These carbon nanotubes are having extraordinary thermal conductivity and good mechanical, electrical properties. So it is applied in nanotechnology, electronics, optics and other fields of material science and technology (Balamurugan et al., 2012).

Eswai et al., (2006) conducted his research on dispersion carbon nanotubes in aluminium powder. By his 


\section{Syed Bava Bakrudeen and Balaji}

results he concluded that mechanical alloying was a promising technique of mixing carbon nanotube with aluminium. SEM results showed that individual nanotubes were well embedded in the aluminium matrix. So here if we want to mix the aluminium (1100) with carbon nanotubes, we should use stir casting method.

Balamurugan et al., (2012) conducted experiments on Aluminium (1100) and they mixed Aluminium (1100) with different percentage $(2 \%, 3 \%$ and $4 \%)$ of Carbon nano tube using stir casting method. After that they found Aluminium (1100) with $4 \%$ of Carbon nanotube (AlCNT4\%) composite properties are increased when compared to Aluminium (1100). They concluded that hardness was increased by $12.75 \%$, yield tensile strength was increased by $25 \%$ and $\mathrm{Al}-\mathrm{CNT} 4 \%$ was thermally more stable than aluminium (1100).

In an another experiment which is conducted by Balamurugan et al., (2012) on Aluminium (1100). In their experiment they mixed Aluminium (1100) with different percentage $(5 \%, 10 \%, 15 \%$ and $20 \%)$ of silicon carbide using stir casting method. Finally, they found that Aluminium (1100) with $10 \%$ of silicon carbide composite hardness is $18 \%$ higher than that of Aluminium (1100) and Aluminium (1100) with $15 \%$ of silicon carbide composites showed ultimate tensile strength of about $36 \%$ higher than that of aluminium (1100).

\section{MATERIALS AND METHOD}

Aluminium (1100) and Al-CNT4\% were used for design and analysis of butterfly valve. The aluminium (1100) has density of $2700 \mathrm{~kg} / \mathrm{m}^{3}$, elastic modulus of 80 $\mathrm{GPa}$, poission ratio of 0.33 , thermal conductivity of 218 $\mathrm{w} / \mathrm{mk}$ and coefficient of thermal expansion of $23.6 \times 10^{-6} /{ }^{0} \mathrm{C}$ at $20-100^{\circ} \mathrm{C}$.

According to Balamurugan et al., (2012) physical and thermal properties of Aluminium with carbon nano tube, the coefficient of thermal expansion of aluminium (1100) is $0.045 \times 10^{-6} /{ }^{0} \mathrm{C}$ at $413^{0} \mathrm{C}$ using automated dilatometer equipment, yield stress is $38.4 \mathrm{MPa}$ and the properties of Al-CNT $4 \%$ composite is $0.009 \times 10^{-6} /{ }^{\circ} \mathrm{C}$ at $387^{0} \mathrm{C}$ using automated dilatometer equipment, yield stress is $48 \mathrm{MPa}$. So these details are used for our analysis purpose using Ansys software.

\section{Experimental Procedure}

The experimental procedure was having two steps, first was butterfly valve design by using Pro-E software and second was analysis of the valve by using Ansys Software (Laxmikanth et al., 2012) with different material like Aluminium (1100) and Al-CNT4\% composite

Design of Butterfly Valve: Butter fly valve having six major parts. The parts are given below.

1. Disc

2. Stem

3. Bolt and nut

4. Body

5. Bush

6. Butterfly valve was designed by using using Pro-E

Disc: Disc is the major portion of butterfly valve to regulate the flow of liquid. It is commonly made of aluminium or cast iron. Disc edge is individually processed through machining and hand buffing for
Sci. Technol. Arts Res. J., Oct-Dec 2013, 2(4): 102-105

smooth edge, providing a bubble tight shut off and maximum seat life. Figure 1 shows the diagram of butterfly valve disc. The diameter and thickness used for the butterfly valve disc was $100 \mathrm{~mm}$ and $20 \mathrm{~mm}$ respectively.

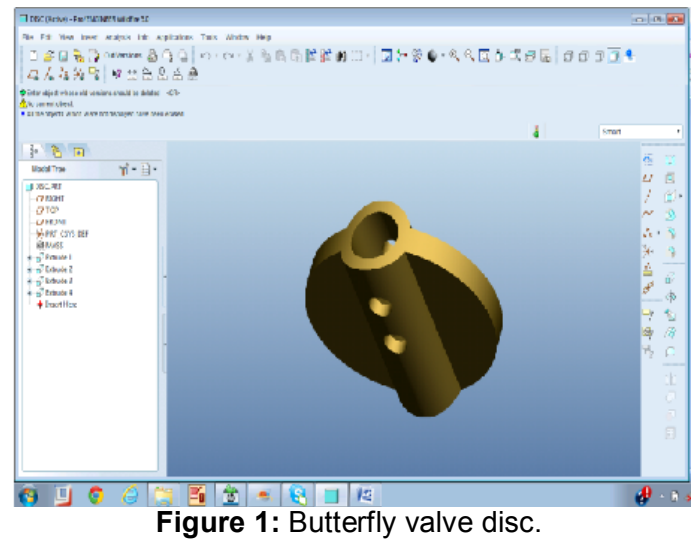

Stem: stem extends through disc and aligns socket in body. Stem end has standard dimensions for operator interchangeability. The stem diameter which is used in our study was $30 \mathrm{~mm}$.

Bolt and Nut: stainless steel bolt and nut securely holds the disc to stem. O ring seal prevents the leakage in stem area and creates positive connection. The bolt size which is used for the design was M10

Body: The outer body was build with flanges for fixing the bolt and nut. So it is able to fix the required pipe line. Body machined to high tolerances. Guaranteed standard dimensions for interchangeability of parts and actuators. The inner diameter of body was $105 \mathrm{~mm}$, outer diameter of body (Flange) was $150 \mathrm{~mm}$ and the thickness of body was $40 \mathrm{~mm}$.

Bush: Bush protects the disc from side thrust. They are made up of impact and corrosion resistant material. Commonly the bush is made by flexible material like Rubber and Elostomers. Figure 2 shows complete assembly of butterfly valve. The inner diameter of bush was $100 \mathrm{~mm}$, outer diameter of bush was 105 to $106 \mathrm{~mm}$ and the thickness of Bush was $30 \mathrm{~mm}$.

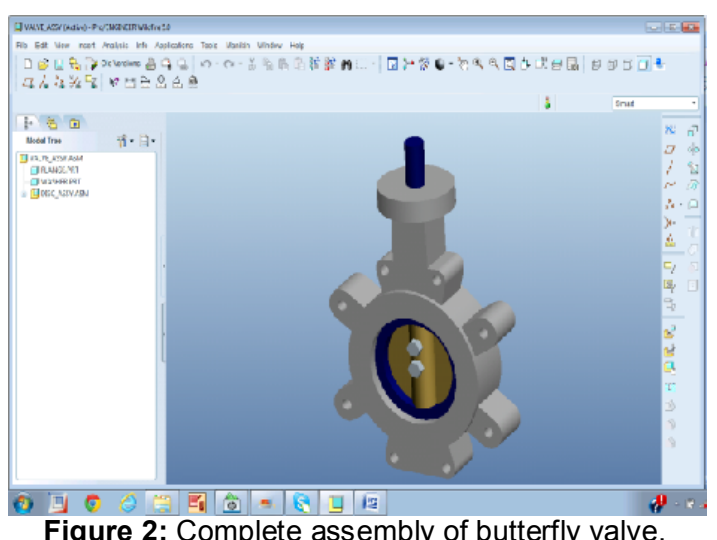

Analysis of Butterfly Valve

The analysis of butterfly valve has two stages. First stage is we want to analysis with aluminium (1100) next we want to analysis Al-CNT4\% composite. The ANSYS 12.0 software was used for the analysis purpose. 
Syed Bava Bakrudeen and Balaji

\section{Aluminium (1100) Analysis}

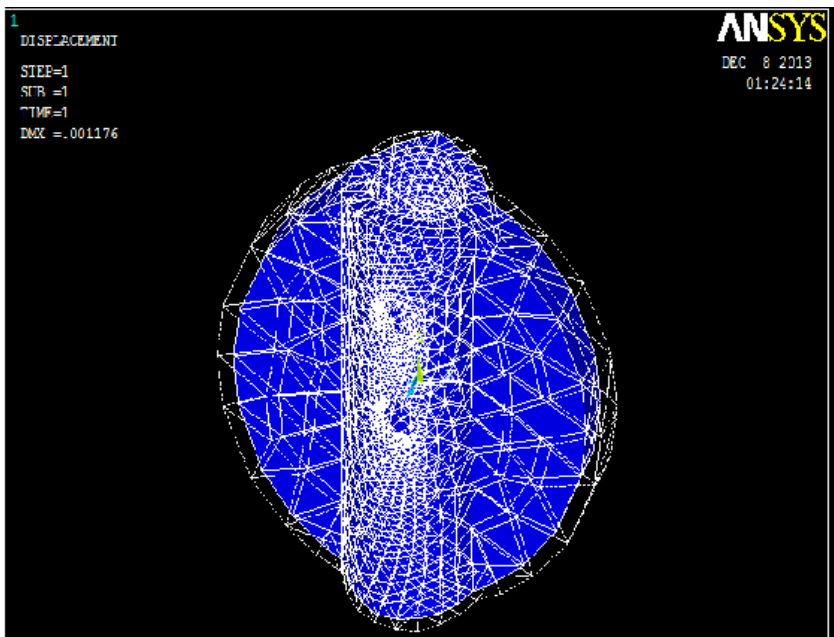

Figure 3: Disc was subjected to $100 \mathrm{~N} / \mathrm{m}^{2}$ pressure and the maximum deflection was $0.001176 \mathrm{~m}$.

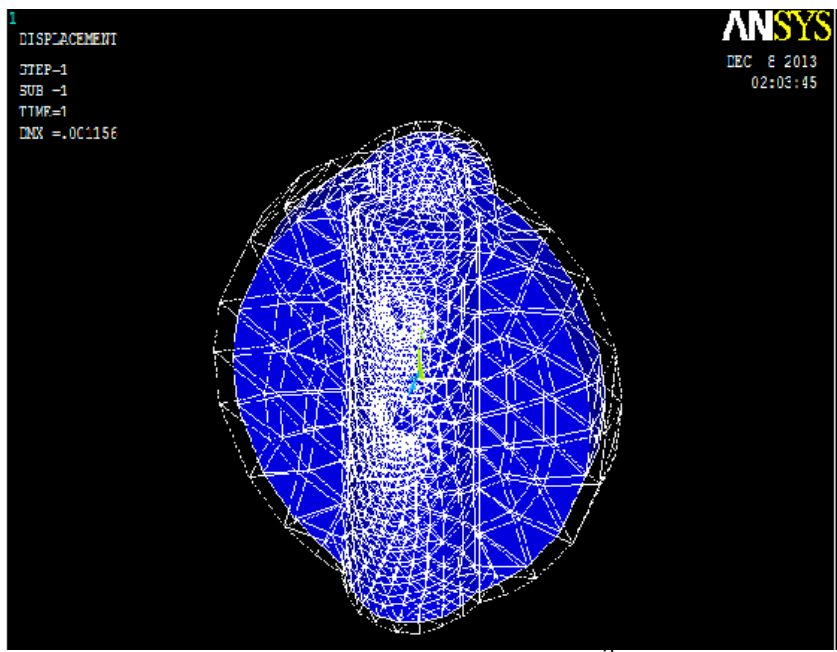

Figure 4: Disc was subjected to $250 \mathrm{~N} / \mathrm{m}^{2}$ pressure and the maximum deflection was $0.001156 \mathrm{~m}$.

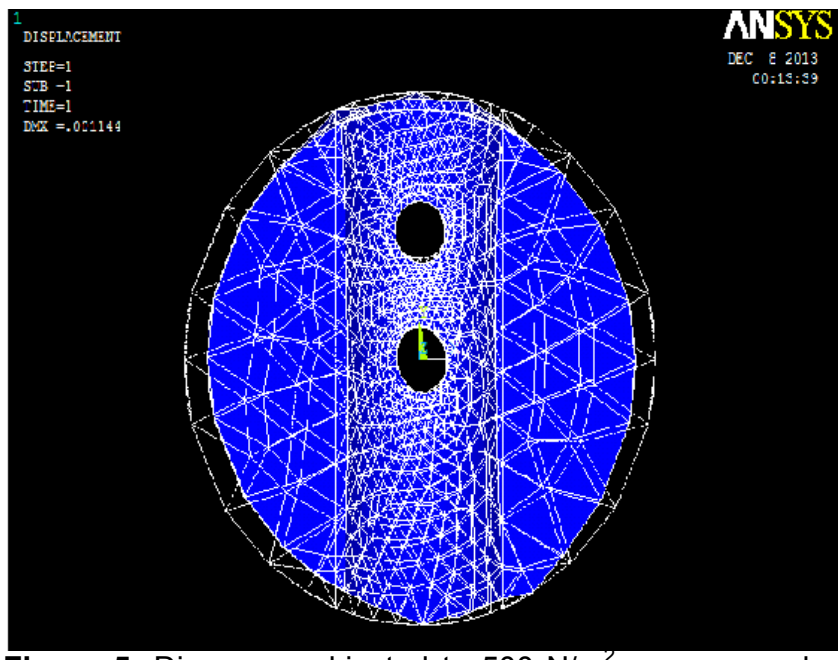

Figure 5: Disc was subjected to $500 \mathrm{~N} / \mathrm{m}^{2}$ pressure and the maximum deflection was $0.00114 \mathrm{~m}$
Sci. Technol. Arts Res. J., Oct-Dec 2013, 2(4): 102-105

\section{Al-CNT4\% Composite Analysis}

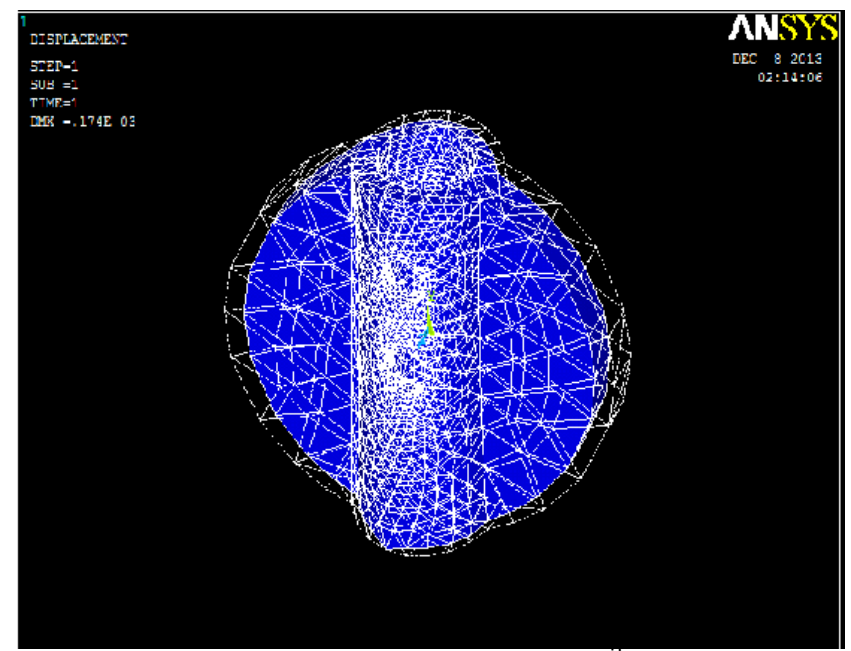

Figure 6: Disc was subjected to $100 \mathrm{~N} / \mathrm{m}^{2}$ pressure and the maximum deflection was $0.174 \times 10^{-3} \mathrm{~m}$.
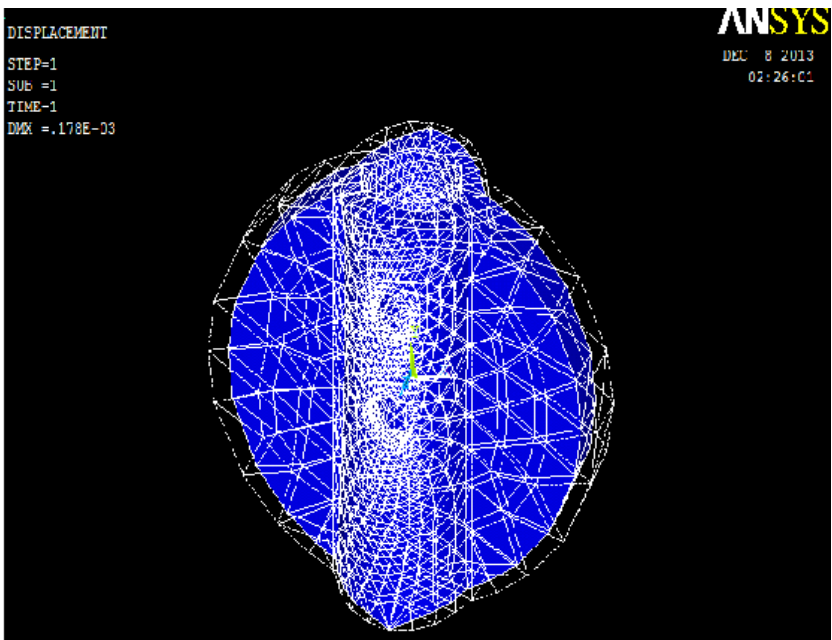

Figure 7: Disc was subjected to $250 \mathrm{~N} / \mathrm{m}^{2}$ pressure and the maximum deflection was $0.178 \times 10^{-3} \mathrm{~m}$.

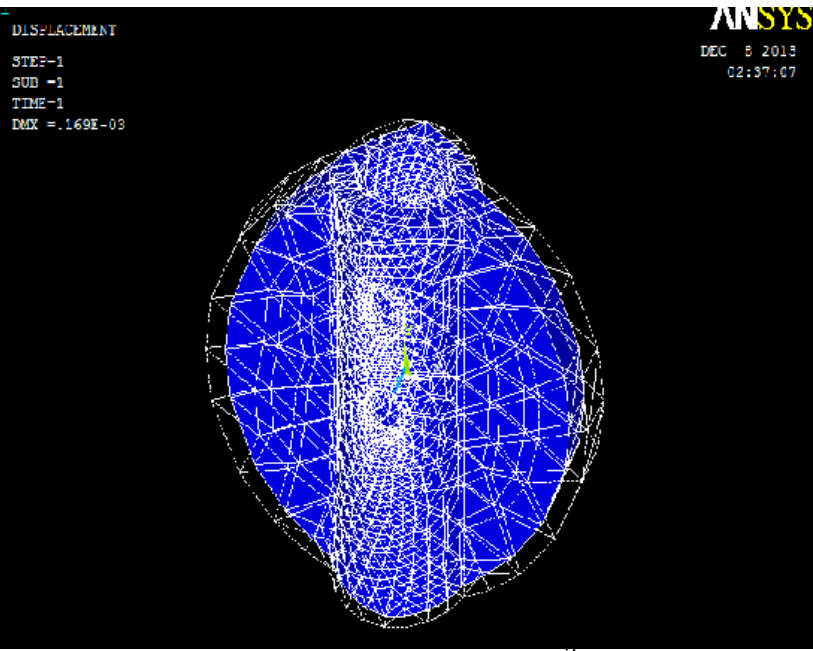

Figure 8: Disc was subjected to $500 \mathrm{~N} / \mathrm{m}^{2}$ pressure and the maximum deflection was $0.169 \times 10^{-3} \mathrm{~m}$. 


\section{Syed Bava Bakrudeen and Balaji}

\section{RESULT AND DISCUSSION}

The table 1 shows the details about the maximum deflection of butterfly valve disc for applying different pressure values and using Aluminium (1100) as a material. In aluminium (1100) the maximum deflection of the entire pressure category in my all analysis is almost same, so the value is $0.001176 \mathrm{~m}$ or $1.176 \mathrm{~mm}$

Table 1: Maximum deflection of butterfly valve disc for applying different pressure values and using Aluminium (1100) as a material.

\begin{tabular}{cccc}
\hline \multirow{2}{*}{ S.No } & $\begin{array}{c}\text { Pressure } \\
\text { in N/m }\end{array}$ & \multicolumn{2}{c}{ Deflection in Meter } \\
\cline { 3 - 4 } & 100 & In Meter & In Millimeter \\
\hline 1 & 250 & 0.001176 & 1.176 \\
2 & 500 & 0.001156 & 1.156 \\
3 & &
\end{tabular}

The table 2 shows the details about the maximum deflection of butterfly valve disc for applying different pressure values and using Al-CNT-4\% as a material. In the Al-CNT-4\% material the maximum deflection of the entire pressure category in my all analysis is almost same, so the value is $0.174 \times 10^{-3} \mathrm{~m}$ or $0.174 \mathrm{~mm}$.

Table 2: Maximum deflection of butterfly valve disc for applying different pressure values and using Al$\mathrm{CNT}-4 \%$ as a material.

\begin{tabular}{|c|c|c|c|}
\hline \multirow{2}{*}{ S.No } & \multirow{2}{*}{$\begin{array}{c}\text { Pressure } \\
\text { in } N / \mathrm{m}^{2}\end{array}$} & \multicolumn{2}{|c|}{ Deflection in Meter } \\
\hline & & In Meter & In Millimeter \\
\hline 1 & 100 & $0.174 \times 10^{-3}$ & 0.174 \\
\hline 2 & 250 & $0.178 \times 10^{-3}$ & 0.178 \\
\hline 3 & 500 & $0.169 \times 10^{-3}$ & 0.169 \\
\hline
\end{tabular}

The Figure 9 shows the comparative chart of pressure versus deflection for aluminium and Al-CNT4\%. According to the table and chart the Al-CNT4\% has less deflection compare to aluminium (1100). So Al-CNT4\% is mechanically very stable compare to aluminium (1100).

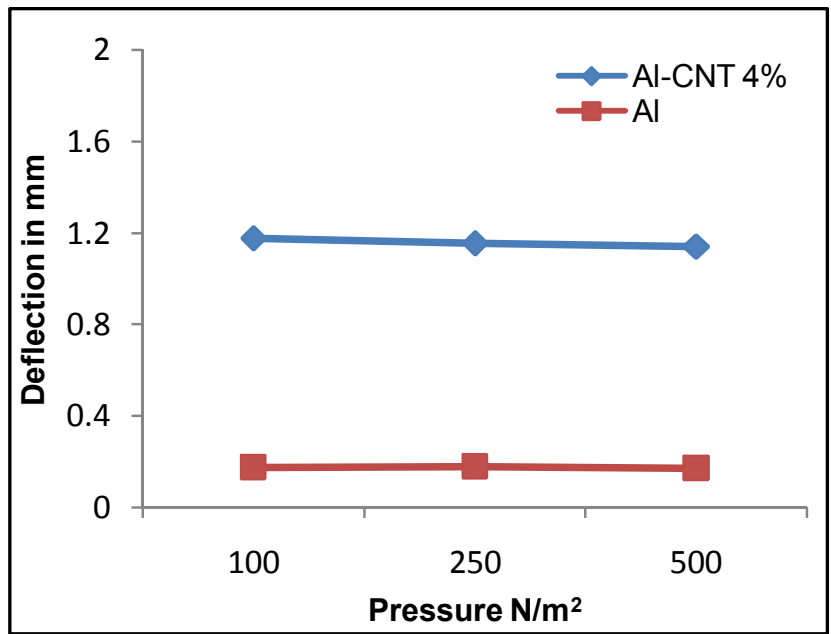

Figure 9: Comparative chart of pressure versus deflection for aluminium (1100) and Al-CNT4\%.

In aluminium (1100) the maximum deflection of the entire pressure category in my all analysis is almost
Sci. Technol. Arts Res. J., Oct-Dec 2013, 2(4): 102-105

same, so the value is $1.176 \mathrm{~mm}$. In Al-CNT4\% composite analysis also the maximum deflection of the entire pressure category is almost same, so the value is 0.178 $\mathrm{mm}$. The amount of decrease in maximum deflection is $0.998 \mathrm{~mm}$ and the percentage of decrease is $84.86 \%$.

\section{CONCLUSION}

The result of the present study reveals that the amount of deflection in Al-CNT4\% composite is around 7 times lesser than aluminium (1100). So taking deflection in to consideration that $\mathrm{Al}-\mathrm{CNT} 4 \%$ is more stable than that of aluminium (1100) for the application of butterfly valve disc. Furthermore, study needs further research for standardization and for its application.

\section{ACKNOWLEDGEMENTS}

The authors expressing profuse gratitude especially to Mr. Weldie Dimtsu, Dean, College of Engineering and Technology, Mr. Yared, Dean/Research, College of Engineering and Technology, and $\mathrm{Mr}$ Equbamariam Leake HOD/ Mechanical Department, Aksum University who facilitated sophisticated laboratories to accomplish this research project has been greatly admired.

\section{REFERENCES}

Balamurugan, Hari Prasad and Syed Bava Bakrudeen., (2012). Investigation of Physical and Thermal properties of Aluminium (1100) with Carbon nanotube. International Journal of Science, Engineering and Technology Research 1(6): 74-79.

Balamurugan., Hari Prasad and Syed Bava Bakrudeen. (2012). Contemplation of Mechanical and Thermal properties of Aluminium (1100) with Silicon Carbide. International Journal of Engineering and Advanced Technology 2(2): 252-259.

Bayraktar, E., Masounave, J., Caplain, R., Bathias, C. (2008). Manufacturing and damage mechanisms in metal matrix composites, Journal of Achievements in Materials and Manufacturing Engineering 31(2): 294-300.

Dobrzaski, L.A., Kremzer, M., Nowak, A.J., Nagel, A. (2009). Aluminium matrix composites fabricated by infiltration method. Archives of Materials Science and Engineering 36(1): 5-11.

Duraes, L., Costa, B.F.O., Santos, R., Correia, A.., Campos, J., Portugal, A. (2007). Fe2O3/aluminum thermite reaction intermediate and final products characterization. Materials Science and Engineering 465: 199-210.

Esawi, A., Morsi, K. (2006). Dispersion of carbon nanotubes (CNTs) in aluminum powder. Part A: Applied Science and Manufacturing 38: 646-650.

Graham Brett., Marc Riveland., Terrence C. Jensen and Theodore J. Heindel, (2011). Cavitation from a Butterfly Valve: Comparing 3D Simulations to 3D X-Ray Computed Tomography Flow Visualization. ASME-JSME-KSME 2011 Joint Fluids Engineering Conference: Volume 2, Fora, Hamamatsu, Japan, July 24-29, 2011paper No. AJK2011-33003, pp. 161-169, 24-29 July, 2011.

Laxmikant, D., Rangari, P.M., Zode, P.G., Mehar. (2012). Stress Analysis of LPG Cylinder Using Ansys Software in IJERA, 2(4): 2278-2281

Li Qianqian., Christian, A., Rottmair F. Robert. (2010). CNT reinforced light metal composites produced by melt stirring and by high pressure die casting. Journal of Membrane Science 500: 200-210. 